\title{
A preoperative mortality risk assessment model for Stanford type A acute aortic dissection
}

Juntao Kuang ${ }^{1,2 \dagger}$, Jue Yang ${ }^{1 \dagger}$, Qiuji Wang ${ }^{1,2}$, Changjiang Yu ${ }^{1}$, Ying $\mathrm{Li}^{1,3}$ and Ruixin Fan ${ }^{1 *}$ (D)

\begin{abstract}
Background: Acute aortic dissection type $A$ is a life-threatening disease required emergency surgery during acute phase. Different clinical manifestations, laboratory tests, and imaging features of patients with acute aortic dissection type $\mathrm{A}$ are the risk factors of preoperative mortality. This study aims to establish a simple and effective preoperative mortality risk assessment model for patients with acute aortic dissection type A.

Methods: A total of 673 Chinese patients with acute aortic dissection type A who were admitted to our hospital were retrospectively included. All patients were unable to receive surgically treatment within 3 days from the onset of disease. The patients included were divided into the survivor and deceased groups, and the endpoint event was preoperative death. Multivariable analysis was used to investigate predictors of preoperative mortality and to develop a prediction model.
\end{abstract}

Results: Among the 673 patients, 527 patients survived (78.31\%) and 146 patients died (21.69\%). The developmental dataset had 505 patients, calibration by Hosmer Lemeshow was significant $\left(X^{2}=3.260, \mathrm{df}=8, P=0.917\right)$ and discrimination by area under ROC curve was 0.8448 (95\% Cl 0.8007-0.8888). The validation dataset had 168 patients, calibration was significant $\left(X^{2}=5.500, \mathrm{df}=8, P=0.703\right)$ and the area under the $\mathrm{ROC}$ curve was $0.8086(95 \% \mathrm{Cl} 0.7291-$ $0.8881)$. The following independent variables increased preoperative mortality: age $(\mathrm{OR}=1.008, P=0.510)$, abrupt chest pain $(\mathrm{OR}=3.534, P<0.001)$, lactic in arterial blood gas $\geq 3 \mathrm{mmol} / \mathrm{L}(\mathrm{OR}=3.636, P<0.001)$, inotropic support $(\mathrm{OR}=8.615, P<0.001)$, electrocardiographic myocardial ischemia $(\mathrm{OR}=3.300, P=0.001)$, innominate artery involvement $(O R=1.625, P=0.104)$, right common carotid artery involvement $(O R=3.487, P=0.001)$, superior mesenteric artery involvement $(\mathrm{OR}=2.651, P=0.001)$, false lumen / true lumen of ascending aorta $\geq 0.75(\mathrm{OR}=2.221, P=0.007)$. Our data suggest that a simple and effective preoperative death risk assessment model has been established.

Conclusions: Using a simple and effective risk assessment model can help clinicians quickly identify high-risk patients and make appropriate medical decisions.

Keywords: Type A aortic dissections, Preoperative mortality, Scoring model

*Correspondence: fanruixin@163.com

†Juntao Kuang and Jue Yang have contributed equally to this work

${ }^{1}$ Department of Cardiovascular Surgery, Guangdong Provincial

Cardiovascular Institute, Guangdong Provincial People's Hospital,

Guangdong Academy of Medical Sciences, Guangzhou 510080, China

Full list of author information is available at the end of the article

\section{Background}

Acute aortic dissection (AAD) is a rare life-threatening condition, and its diagnosis and treatment still remain a challenge. According to the Stanford classification, AADs involving the ascending aorta are classified as type A dissections [1]. Acute aortic dissection type A (AADA) usually requires emergency surgery in the acute

(c) The Author(s) 2020. Open Access This article is licensed under a Creative Commons Attribution 4.0 International License, which permits use, sharing, adaptation, distribution and reproduction in any medium or format, as long as you give appropriate credit to the original author(s) and the source, provide a link to the Creative Commons licence, and indicate if changes were made. The images or other third party material in this article are included in the article's Creative Commons licence, unless indicated otherwise in a credit line to the material. If material is not included in the article's Creative Commons licence and your intended use is not permitted by statutory regulation or exceeds the permitted use, you will need to obtain permission directly from the copyright holder. To view a copy of this licence, visit http://creativecommons.org/licenses/by/4.0/. The Creative Commons Public Domain Dedication waiver (http://creativeco mmons.org/publicdomain/zero/1.0/) applies to the data made available in this article, unless otherwise stated in a credit line to the data. 
phase. Without surgery, $50 \%$ of patients die within $24 \mathrm{~h}$ of disease onset, and the mortality rate is approximately $1-2 \%$ per hour [2]. The absence of mortality risk assessment may affect medical decision-making and resource allocation for high-risk patients and even hinder their treatment, because only timely surgical management can benefit the most patients in this group [3]. Moreover, risk stratification helps eliminate bias in high-risk patients [4]. By establishing a mortality risk assessment model, the risk of surgery can be comprehensively assessed preoperatively and the best treatment strategy can be selected, thereby reducing mortality and the incidence of complications.

Currently, several preoperative risk assessment models for cardiac surgery have been developed, such as Parsonnet model [5], European System for Cardiac Operative Risk Evaluation (Euro SCORE) [6] and Euro SCORE II [7]. These models have been widely used for assessing early preoperative mortality in various cardiac procedures. However, these scoring systems used for patients undergoing conventional cardiac surgery are not suitable for patients with AADA [8, 9]. Although there have been some risk prediction models for aorta-related surgery have been established in recent years, these models cannot be widely adopted widely because of limitations in the studies analyzing their efficacy, such as small sample sizes and inappropriate variable selection. Considering the above limitations, the predictive performance of these models is rendered questionable. Additionally, these models are based on patient samples taken from developed countries, and the models are focused on the analysis of surgical risk in patients receiving surgical treatment [3, 10-12]. A comprehensive risk assessment has rarely been performed on preoperative patients or patients awaiting surgery in the emergency department. Compared with foreign literature reports, the diagnosis and treatment of aortic dissection (AD) in China have the following characteristics: diversified clinical manifestations, younger age of onset, higher mortality during hospitalization and in the preoperative period, as well as, and more complications postoperatively [13]. Moreover, it usually takes a longer time from the onset of $A D$ to surgical treatment for patients in developing countries. In China it takes between 2-7 days for a patient with $\mathrm{AD}$ onset to undergo surgical treatment, compared to only $4.5 \mathrm{~h}$ on average in developed countries [14]. The preoperative mortality rate of patients with AADA has not been clearly evaluated in large samples. Therefore, a preoperative mortality risk scoring system suitable for developing countries' patients is urgently required for predicting the risk of early death and for establishing emergency room guidelines in various institutions. This study aimed to establish a simple and effective risk assessment model for evaluating preoperative death risk in 673 patients with AADA within 3 days from the onset of the dissection.

\section{Methods}

In total, 673 consecutive patients with AADA admitted to Guangdong Provincial People's Hospital between September 2017 and June 2020 were recruited, including local newly diagnosed patients in the hospital and those who were transferred to our center from other hospitals. Patients who did not undergo acute surgical treatment within 3 days from symptom onset were included. The time of onset was defined as the time when the patient first complained of severe pain in the chest or other parts, or when patients without pain complaint underwent examination and had a diagnosis of AADA. All patients were diagnosed using transthoracic echocardiography (TTE) and computed tomography angiography (CTA). Patient data, including general conditions, history, clinical manifestations, comorbidities, physical examination, laboratory tests, and imaging data, were collected (Tables 1, 2, 3). For data collection, data from our institution were given priority over from other institutions. If transferred patients were unable to undergo examinations at our institution owing to their critical condition, the data from other institutions would be collected. All data are collected and entered by specialists and reviewed by experienced and senior doctors.

\section{Statistical analysis}

Patients included in the study were divided into the survivor and deceased groups. The endpoint event was preoperative death. The data were divided into a developmental dataset (505 patients) and a validation dataset (168 patients) using simple random sampling. Normally distributed continuous variables were reported as mean and standard deviation and were compared using by a two-tailed t-test. Non-normally distributed continuous variables were reported as median and quartile ranges and were compared using the Mann-Whitney $U$ test. Categorical variables were reported as frequency and percentage and were analyzed using by $x^{2}$ or Fisher's exact test as needed. The stepwise multivariate analysis was performed for determining the variables that were independently associated with preoperative mortality. Odds ratios (OR) were presented with corresponding 95\% confidence intervals $(\mathrm{CI})$ and $P$ values; $P<0.05$ was considered statistically significant. By entering the variables with $P<0.05$ into the logistic regression multivariate analysis, the formula was as follows: $\operatorname{logit} \mathrm{p}=\ln [\mathrm{p} /(1-$ $\mathrm{p})]=\mathrm{B}_{0} \mathrm{X}_{0}+\mathrm{B}_{1} \mathrm{X}_{1}+\cdots+\mathrm{B}_{\mathrm{k}} \mathrm{X}_{\mathrm{k}}$. In this formula, $\mathrm{p}$ denotes preoperative death, and each $B$ value was expressed as 
Table 1 Demographic data, history, and presenting symptoms of patients with preoperative acute aortic dissection type A

\begin{tabular}{|c|c|c|c|}
\hline Variable & Alive $(n=527)$ & Deceased $(n=146)$ & Total $(n=673)$ \\
\hline DeBakey II & $74(14.04)$ & $17(11.64)$ & $91(13.52)$ \\
\hline Age, y & $53.70 \pm 13.12$ & $56.23 \pm 12.39$ & $54.25 \pm 13.00$ \\
\hline Female & $92(17.46)$ & $31(21.23)$ & $123(18.28)$ \\
\hline Abrupt chest pain & $311(59.01)$ & $113(77.40)$ & $424(63.00)$ \\
\hline Hypertension & $310(58.82)$ & $81(55.48)$ & $391(58.10)$ \\
\hline Neurological disease & $37(7.02)$ & $19(13.01)$ & $56(8.32)$ \\
\hline Marfan syndrome & $30(5.69)$ & $7(4.79)$ & $37(5.50)$ \\
\hline Prior cardiovascular diseases & $50(9.49)$ & $10(6.85)$ & $60(8.92)$ \\
\hline Prior cardiovascular surgery & $49(9.30)$ & $9(6.16)$ & $58(8.62)$ \\
\hline Smoking & $158(29.98)$ & $46(31.51)$ & $204(30.31)$ \\
\hline $\begin{array}{l}\text { Anticoagulant and antiplatelet medication within } \\
\text { the past month }\end{array}$ & $42(7.97)$ & $5(3.42)$ & $47(6.98)$ \\
\hline Inotropic support & $37(7.02)$ & $51(34.93)$ & $88(13.08)$ \\
\hline Ventilation & $12(2.28)$ & $17(11.64)$ & $29(4.31)$ \\
\hline
\end{tabular}

Continuous variables are reported as mean and standard deviation, and categorical variables are reported as numbers (\%)

Table 2 Laboratory data of patients with preoperative acute aortic dissection type A

\begin{tabular}{llll}
\hline Variable & Alive $(\mathbf{n}=\mathbf{5 2 7})$ & Deceased $(\mathbf{n}=\mathbf{1 4 6})$ & Total $(\mathbf{n}=\mathbf{6 7 3})$ \\
\hline $\mathrm{LaC}$ in $\mathrm{ABG} \geq 3 \mathrm{mmol} / \mathrm{L}$ & $112(21.25)$ & $57(39.04)$ & $169(25.11)$ \\
$\mathrm{CTnT} \geq 200 \mathrm{pg} / \mathrm{mL}$ & $38(7.21)$ & $21(14.38)$ & $59(8.77)$ \\
$\mathrm{WBC} \geq 15 \times 10^{9} / \mathrm{L}$ & $144(27.32)$ & $60(41.10)$ & $204(30.31)$ \\
$\mathrm{RBC}<3.5 \times 10^{12} / \mathrm{L}$ & $41(7.78)$ & $20(13.70)$ & $61(9.06)$ \\
$\mathrm{Hb}<90 \mathrm{~g} / \mathrm{L}$ & $13(2.47)$ & $11(7.53)$ & $24(3.57)$ \\
$\mathrm{ALT} \geq 200 \mathrm{U} / \mathrm{L}$ & $23(4.36)$ & $23(15.75)$ & $46(6.84)$ \\
$\mathrm{AST} \geq 120 \mathrm{U} / \mathrm{L}$ & $50(9.49)$ & $39(26.71)$ & $89(13.22)$ \\
$\mathrm{CREA} \geq 177 \mu \mathrm{mol} / \mathrm{L}$ & $66(12.52)$ & $35(23.97)$ & $101(15.01)$ \\
APTT $\geq 55 \mathrm{~s}$ & $30(5.69)$ & $14(9.59)$ & $44(6.54)$ \\
D-dimmer $\geq 12,000 \mathrm{ng} / \mathrm{mL}$ & $206(39.09)$ & $95(65.07)$ & $301(44.73)$ \\
\hline
\end{tabular}

Categorical variables are reported as numbers (\%)

Lac, lactic acid; ABG, arterial blood gas; CTnT, Troponin T; WBC, white blood cell; RBC, red blood cell; $\mathrm{Hb}$, hemoglobin; ALT, alanine aminotransferase; AST, aspartate aminotransferase; CREA, serum creatinine; APTT, activated partial thromboplastin time

a coefficient to an independent risk factor in the final model of a particular risk.

By comparing the observed and predicted mortalities the model was then tested on the validation dataset for calibration and using the area under the receiver operating characteristic (ROC) curve for discrimination. The goodness of fit of the final model was tested using the Hosmer-Lemeshow test. In addition, tenfold crossvalidation was conducted by dividing the dataset into 10 equally sized samples at random, refitting the model to each of the 10 sets comprising $90 \%$ of the data, calculating the area under the ROC curve for the unused $10 \%$ in each case and averaging over 10 areas under the ROC curves. Exclude variables with missing rates greater than
$20 \%$. Missing data are not filled in. Statistical data analysis was performed using SAS 9.4 (Cary, NC, USA).

\section{Results}

\section{Univariate risk factors for death}

Most of the patients are yellow, from the southern provinces of China. Among 673 patients, 146 (21.64\%) patients died prior to surgery within 3 days after the onset of the disease. There were 550 men $(81.72 \%)$ and 123 women $(18.28 \%)$ patients, with an average age of $54.25( \pm 13.00)$ years. The variables associated with preoperative mortality including age, abrupt chest pain, inotropic support and ventilation (Table 4). Other statistically significant univariate risk factors included lactic 
Table 3 Imaging features of patients with acute aortic dissection type A

\begin{tabular}{llll}
\hline Variable & Alive $(\mathbf{n = 5 2 7})$ & Deceased $(\mathbf{n = 1 4 6 )}$ & Total $(\mathbf{n}=\mathbf{6 7 3})$ \\
\hline EF $\leq 50 \%$ & $21(3.98)$ & $19(13.01)$ & $87(12.93)$ \\
Average ascending aorta diameter by $T T E \geq 55 \mathrm{~mm}$ & $54(10.25)$ & $33(22.60)$ & $87(12.93)$ \\
Aortic insufficiency & $342(64.90)$ & $110(75.34)$ & $452(67.16)$ \\
Severe & $68(12.90)$ & $21(14.38)$ & $89(13.22)$ \\
Moderate & $85(16.13)$ & $26(17.81)$ & $111(16.49)$ \\
Minor & $189(35.86)$ & $63(43.15)$ & $252(37.44)$ \\
Moderate or massive pericardial effusion & $33(6.26)$ & $22(15.07)$ & $55(8.17)$ \\
Electrocardiographic myocardial ischemia & $54(10.25)$ & $35(23.97)$ & $39(13.22)$ \\
Sinotubular junction diameter by CTA $\geq 55 \mathrm{~mm}$ & $22(4.17)$ & $16(10.96)$ & $38(5.65)$ \\
Ascending aorta diameter by CTA $\geq 55 \mathrm{~mm}$ & $84(15.94)$ & $28(19.18)$ & $112(16.64)$ \\
FL/TL of the ascending aorta $\geq 0.75$ & $117(56.00)$ & $40(27.40)$ & $157(23.33)$ \\
FL/TL of the thoracic aorta $\geq 0.75$ & $71(13.47)$ & $39(26.71)$ & $110(16.34)$ \\
FL/TL of the abdominal aorta $\geq 0.75$ & $40(7.59)$ & $25(17.12)$ & $65(9.66)$ \\
Patent false lumen & $207(39.28)$ & $93(63.70)$ & $300(44.58)$ \\
RCCA involvement & $76(14.42)$ & $41(28.08)$ & $117(17.38)$ \\
IA involvement & $222(42.13)$ & $90(61.64)$ & $312(46.36)$ \\
SMA involvement & $140(26.57)$ & $68(46.58)$ & $208(30.91)$ \\
RA involvement & $280(53.13)$ & $97(61.64)$ & $342(50.82)$ \\
CIA involvement & $252(47.82)$ & $90(61.64)$ & $342(50.82)$ \\
Abdominal aortic aneurysm & $23(4.36)$ & $6(4.11)$ & $29(4.31)$ \\
\hline
\end{tabular}

Categorical variables are reported as numbers (\%)

$E F$, ejection fraction; TTE, transthoracic echocardiography; CTA, computed tomography angiography; FL, false lumen; TL, true lumen; RCCA, right common carotid artery; IA, innominate artery; SMA, superior mesenteric artery; $\mathrm{RA}$, renal artery; $\mathrm{CIA}$, common iliac artery

acid in arterial blood gas (Lac in $\mathrm{ABG}) \geq 3 \mathrm{mmol} / \mathrm{L}$, Troponin $\mathrm{T}(\mathrm{cTnT}) \geq 200 \mathrm{pg} / \mathrm{mL}$, white blood cell count $(\mathrm{WBC}) \geq 15 \times 10^{9} / \mathrm{L}, \quad \mathrm{D}$-dimmer $\geq 12,000 \mathrm{ng} / \mathrm{mL}$, ejection fraction $(\mathrm{EF}) \leq 50 \%$, moderate or massive pericardial effusion, electrocardiographic myocardial ischemia, CTA measured sinotubular junction diameter of $\geq 55 \mathrm{~mm}$, patent false lumen, and right common carotid artery (RCCA) involvement. (Tables 2, 3). No statistically significant difference was observed between the survivor and deceased groups [84 (15.94\%) vs. 28 (19.18\%), $P=0.299]$ in the CTA measured ascending aorta diameter of $\geq 55 \mathrm{~mm}$. However, in the average ascending aorta diameter measured using TTE, there was a statistically significant difference between the groups [54 (10.25\%) vs. 33 (22.60\%), $P<0.001$ ]. Preoperative death was strongly associated with false lumen (FL)/true lumen (TL) ratio of $\geq 75 \%$ of the ascending aorta, thoracic aorta, and abdominal aorta. Complications from AD had a significant impact on preoperative mortality.

\section{Preoperative prediction model}

In the multivariate logistic regression analysis, the following independent variables increased preoperative mortality: age $(\mathrm{OR}=1.008, P=0.510)$, abrupt chest pain $(\mathrm{OR}=3.534, P<0.001), \mathrm{Lac}$ in $\mathrm{ABG} \geq 3 \mathrm{mmol} / \mathrm{L}$
$(\mathrm{OR}=3.636, P<0.001)$, inotropic support $(\mathrm{OR}=8.615$, $P<0.001)$, electrocardiographic myocardial ischemia $(\mathrm{OR}=3.300, \quad P=0.001), \quad$ innominate artery (IA) involvement $(\mathrm{OR}=1.625, P=0.104)$, RCCA involvement $(\mathrm{OR}=3.487, \quad P=0.001)$, superior mesenteric artery (SMA) involvement $(\mathrm{OR}=2.651, P=0.001)$, FL / TL of the ascending aorta of $\geq 0.75(\mathrm{OR}=2.221$, $P=0.007$ ) (Table 5). Based on the results of the multiple regression analysis, a risk scoring model was established. The formula for preoperative death risk score is as follows: $\log \mathrm{p}=\ln [\mathrm{p} /(1-\mathrm{p})]=-3.83+0.008 \times$ (age) $+1.262 \times($ abrupt chest pain $)+1.291 \times($ Lac in $\mathrm{ABG})+2.154 \times$ (inotropic support $)+1.194 \times($ electrocardiographic myocardial ischemia $)+0.486 \times($ IA involvement $)+1.249 \times($ RCCA involvement $)+0.975 \times(\mathrm{SMA}$ involvement $)+0.798 \times(\mathrm{FL} / \mathrm{TL}$ of the ascending aorta of $\geq 0.75$ ). The Hosmer-Lemeshow goodness of fit for the logistic regression model was significant $\left(\chi^{2}=3.260\right.$, $\mathrm{df}=8, P=0.917)$, and the area under the ROC curve was 0.8448 (95\% CI $0.8007-0.8888$ ). Calibration of the validation dataset was significant $\left(\chi^{2}=5.500, \mathrm{df}=8, P=0.703\right)$, and the area under the ROC curve was 0.8086 (95\% CI 0.7291-0.8881) (Figs. 1 and 2); both the developmental and validation models retained very good discrimination. The resulting average areas of tenfold cross-validation 
Table 4 Variables associated with mortality $(n=505)$

\begin{tabular}{|c|c|c|c|}
\hline Variable & OR & $95 \% \mathrm{Cl}$ & $P$ value \\
\hline Age & 1.015 & $1.001-1.030$ & 0.038 \\
\hline Abrupt chest pain & 2.378 & $1.555-3.637$ & $<0.001$ \\
\hline Inotropic support & 7.108 & $4.412-11.452$ & $<0.001$ \\
\hline Ventilation & 5.654 & $2.635-12.136$ & $<0.001$ \\
\hline $\mathrm{Lac}$ in $\mathrm{ABG} \geq 3 \mathrm{mmol} / \mathrm{L}$ & 2.404 & $1.616-3.576$ & $<0.001$ \\
\hline $\mathrm{cTnT} \geq 200 \mathrm{pg} / \mathrm{mL}$ & 2.292 & $1.293-4.065$ & 0.005 \\
\hline $\mathrm{WBC} \geq 15 \times 10^{9} / \mathrm{L}$ & 1.938 & $1.317-2.850$ & 0.001 \\
\hline $\mathrm{RBC}<3.5 \times 10^{12} / \mathrm{L}$ & 1.931 & $1.091-3.417$ & 0.024 \\
\hline $\mathrm{Hb}<90 \mathrm{~g} / \mathrm{L}$ & 3.299 & $1.445-7.536$ & 0.005 \\
\hline $\mathrm{ALT} \geq 200 \mathrm{U} / \mathrm{L}$ & 4.188 & $2.271-7.724$ & $<0.001$ \\
\hline $\mathrm{AST} \geq 120 \mathrm{U} / \mathrm{L}$ & 3.801 & $2.368-6.103$ & $<0.001$ \\
\hline CREA $\geq 177 \mu \mathrm{mol} / \mathrm{L}$ & 2.447 & $1.536-3.898$ & $<0.001$ \\
\hline D-dimmer $\geq 12,000 \mathrm{ng} / \mathrm{mL}$ & 3.363 & $2.239-5.052$ & $<0.001$ \\
\hline$E F \leq 50 \%$ & 3.748 & $1.953-7.195$ & $<0.001$ \\
\hline Average ascending aorta diameter by $T T E \geq 55 \mathrm{~mm}$ & 2.650 & $1.635-4.294$ & $<0.001$ \\
\hline \multicolumn{4}{|l|}{ Aortic insufficiency } \\
\hline Severe & 1.843 & $0.988-3.438$ & 0.055 \\
\hline Moderate & 1.825 & $1.017-3.277$ & 0.044 \\
\hline Minor & 1.989 & $1.230-3.216$ & 0.005 \\
\hline Moderate or massive pericardial effusion & 2.656 & $1.496-4.716$ & 0.001 \\
\hline Electrocardiographic myocardial ischemia & 2.789 & $1.737-4.478$ & $<0.001$ \\
\hline CTA measured sinotubular junction diameter of $\geq 55 \mathrm{~mm}$ & 2.892 & $1.475-5.669$ & 0.002 \\
\hline $\mathrm{FL} / \mathrm{TL}$ of the ascending aorta $\geq 0.75$ & 2.269 & $1.529-3.369$ & $<0.001$ \\
\hline $\mathrm{FL} / \mathrm{TL}$ of the thoracic aorta $\geq 0.75$ & 2.418 & $1.548-3.777$ & $<0.001$ \\
\hline $\mathrm{FL} / \mathrm{TL}$ of the abdominal aorta $\geq 0.75$ & 2.592 & $1.511-4.447$ & 0.001 \\
\hline Patent false lumen & 2.930 & $1.983-4.327$ & $<0.001$ \\
\hline RCCA involvement & 2.395 & $1.547-3.709$ & $<0.001$ \\
\hline IA involvement & 2.369 & $1.612-3.481$ & $<0.001$ \\
\hline SMA involvement & 2.528 & $1.724-3.708$ & $<0.001$ \\
\hline RA involvement & 1.890 & $1.272-2.807$ & 0.002 \\
\hline $\mathrm{CIA}$ involvement & 1.877 & $1.278-2.756$ & 0.001 \\
\hline
\end{tabular}

$\mathrm{Cl}$, confidence interval; OR, odds ratio; Lac, lactic acid; ABG, arterial blood gas; CTnT, Troponin T; WBC, white blood cell; RBC, red blood cell; Hb, hemoglobin; ALT, alanine aminotransferase; AST, aspartate aminotransferase; CREA, serum creatinine; EF, ejection fraction; TTE, transthoracic echocardiography; CTA, computed tomography angiography; $\mathrm{FL}$, false lumen; $\mathrm{TL}$, true lumen; $\mathrm{RCCA}$, right common carotid artery; IA, innominate artery; SMA, superior mesenteric artery; RA, renal artery; $\mathrm{CIA}$, common iliac artery

was 0.8057 (range, 0.6986-0.8772), which was very similar to that of the validation set in our initial analysis.

\section{Discussion}

In our study, clinical manifestations, laboratory tests, and imaging features were significantly associated with AADA preoperative deaths. Additionally, a simple and quick bedside scoring model was established which surgeons can quickly use to perform preoperative risk assessments, arrange for the operation, and establish faster channels for effectively treating patients with AADA, especially those deemed to be at high risk for preoperative death. For patients with poor prognoses, model predictions are not necessarily used to deny aggressive treatment.

In agreement with the general cardiac surgery findings $[15,16], A L T \geq 200 \mathrm{U} / \mathrm{L}$ and $\mathrm{AST} \geq 120 \mathrm{U} / \mathrm{L}$ were associated with preoperative death $(P<0.001)$ in our study. Serum albumin level, a widely used evaluation indicator of liver dysfunction, was not measured in most patients in our study, and therefore, was not included as a variable.

In our study, age was a predictive factor, which concurred with the findings of previous studies [11, 17, 18]. Patients' age ranged from 9-91 years, and only 3 patients were $<20$ years old; thus, the model prediction results for young patients might not be accurate. This observation 
Table 5 Preoperative prediction model

\begin{tabular}{|c|c|c|c|c|}
\hline Variable & OR & $95 \% \mathrm{Cl}$ & $\begin{array}{l}\text { Coefficient \& score } \\
\text { assigned }\end{array}$ & $P$ value \\
\hline Age & 1.008 & $0.985-1.030$ & 0.008 & 0.510 \\
\hline Abrupt chest pain & 3.534 & $1.872-6.672$ & 1.262 & $<0.001$ \\
\hline $\mathrm{Lac}$ in $\mathrm{ABG} \geq 3 \mathrm{mmol} / \mathrm{L}$ & 3.636 & $2.047-6.461$ & 1.291 & $<0.001$ \\
\hline Inotropic support & 8.615 & $4.361-17.019$ & 2.154 & $<0.001$ \\
\hline Electrocardiographic myocardial ischemia & 3.300 & $1.621-6.718$ & 1.194 & 0.001 \\
\hline IA involvement & 1.625 & $0.905-2.918$ & 0.486 & 0.104 \\
\hline RCCA involvement & 3.487 & $1.706-7.127$ & 1.249 & 0.001 \\
\hline SMA involvement & 2.651 & $1.527-4.602$ & 0.975 & 0.001 \\
\hline $\mathrm{FL} / \mathrm{TL}$ of the ascending aorta of $\geq 0.75$ & 2.221 & $1.238-3.984$ & 0.798 & 0.007 \\
\hline
\end{tabular}

$\mathrm{Cl}$, confidence interval; $\mathrm{OR}$, odds ratio; $\mathrm{ABG}$, arterial blood gas; $\mathrm{FL}$, false lumen; $\mathrm{TL}$, true lumen; $\mathrm{RCCA}$, right common carotid artery; IA, innominate artery; SMA, superior mesenteric artery

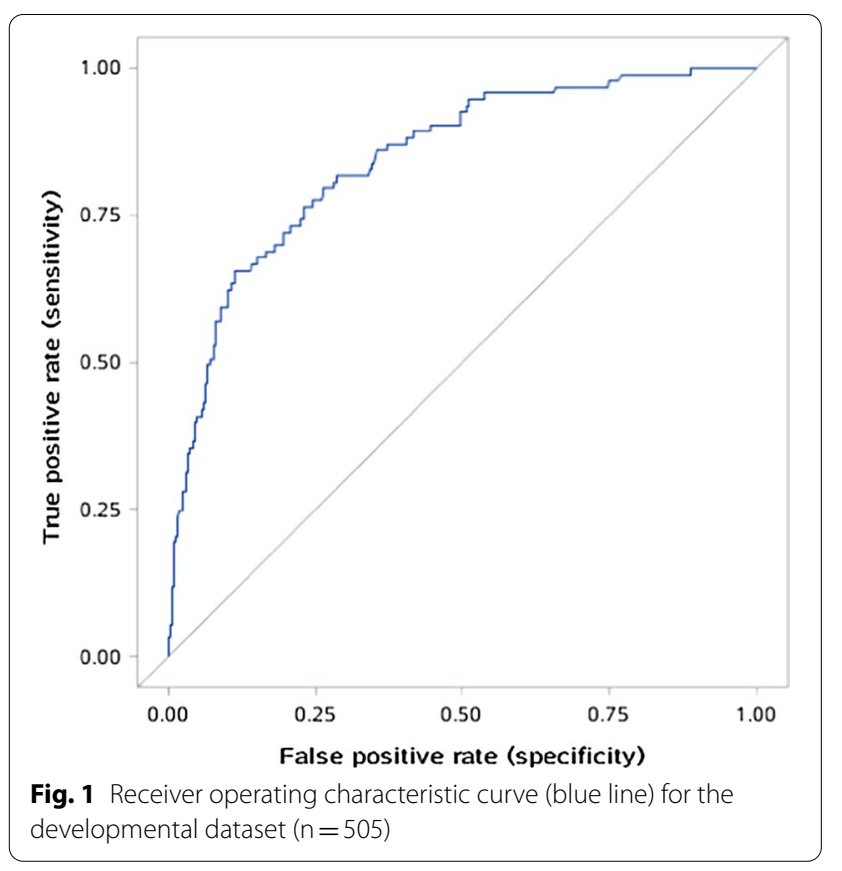

may relate to the longer average time for patients with AADA to undergo surgical treatment in China [14].

The model included variables with electrocardiographic myocardial ischemia. Electrocardiography is very important for the early differential diagnosis of patients with acute severe chest pain owing to the simplicity and convenience of performing this test. AD and coronary heart disease (CHD) are both high-risk cardiovascular diseases, and the case of acute myocardial ischemia (AMI) with AD is a clinically rare critical illness, with a reported incidence of approximately $1-5 \%[19,20]$. It is generally believed that AD can cause AMI. The mechanism involves the intima of the AD

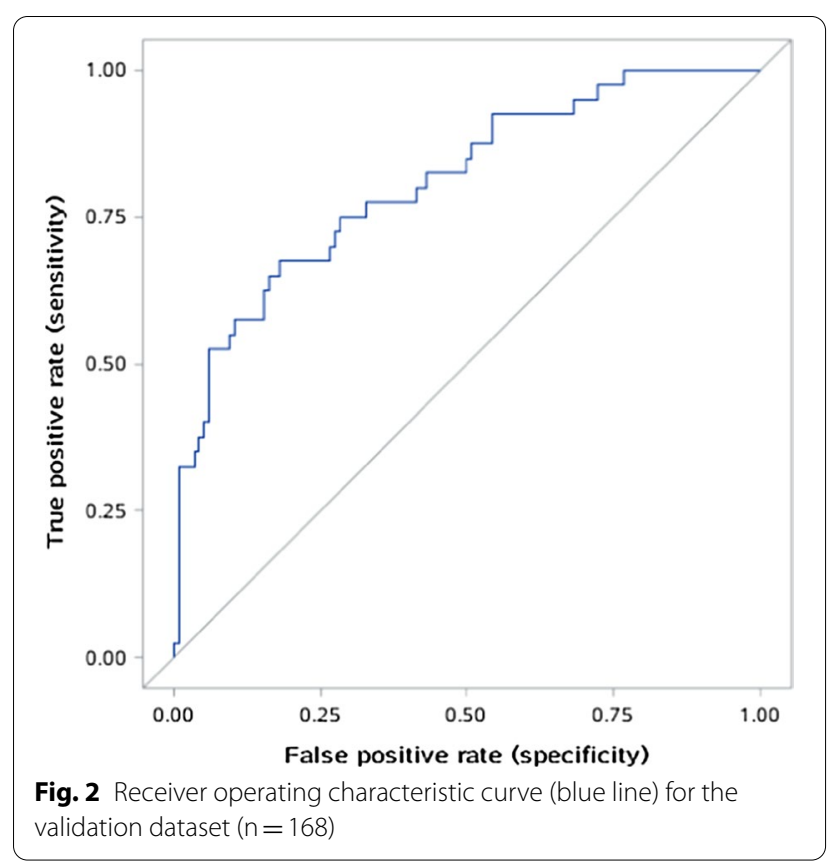

extending to the coronary openings, or the false lumen compressing the coronary artery, resulting in myocardial ischemia and hypoxia, leading to AMI [21, 22]. The variable $\mathrm{CHD}$ was not included in our study, because only a small proportion of patients were diagnosed using coronary angiography or other objective methods; moreover, the definition of CHD and its application in retrospectively collected data may also affect the results in terms of prevalence. Furthermore, in our study, a cTnT level of $\geq 200 \mathrm{pg} / \mathrm{mL}$ was associated with preoperative death $(P=0.005)$. Considering that most patients with angina pectoris had more severe vascular disease, coronary artery stenosis and thrombosis 
caused greater myocardial and vascular damage, which increased cTnT levels.

In our study, the FL/TL ratio of the ascending aorta, thoracic aorta, and abdominal aorta were all $\geq 0.75$ and were statistically significant in the univariate analysis; however, only the FL/TL ratio of the ascending aorta of $\geq 0.75$ was selected among the results of the logistic regression multivariate analysis. Vessel malperfusion could lead to severe complications [12]. The ascending aorta connects the three branches of the aortic arch on its upward course and connects the aortic root on its downward course; the abdominal aorta consists of important abdominal blood vessels, while the thoracic aorta has none. Recently, wall shear stress has been used for evaluating each section of the aorta, and it was found that the aortic arch was in the position prone to rupture in patients with AADA $[23,24]$. We speculated that the ascending aorta malperfusion might be a high-risk factor associated with the extension of rupture. Further study is needed to support this finding.

Ventilation, inotropic support, cardiopulmonary resuscitation, and preoperative syncope are related to inhospital deaths, indicating that patients are in critical condition [11]. In our study, only inotropic support was selected in the final model. We suspected that because the number of patients who underwent these management methods was small and could not be included in the model. Since most patients were referrals from other hospitals, some patients might not have been able to transfer owing to their critical condition; these patients were likely to account for under estimation of the actual incidence.

With each additional malperfused organ system, the risk of mortality and complications increases progressively [25]. Previous studies have shown that coronary artery involvement is an independent risk factor for serious postoperative complications or death, whereas the involvement of the supra-aortic artery or celiac vessels (celiac trunk or SMA) is not a risk factor for mortality or complication rates [26, 27]; however, contradictory results were noted in our study (SMA involvement $[\mathrm{OR}=2.651 ; 95 \%$ CI 1.527-4.602]). Previous studies have reported malperfusion syndrome in $26.7 \%$ of the 221 AADA patients, involving a single organ system in $64.4 \%$, two systems in $27.1 \%$, three in $5.1 \%$, and four in $3.4 \%[28,29]$. In our study, a lower but similar distribution of the involvement of important branches of the aorta (RCCA, IA, SMA, RA, CIA) was observed: one in $17.7 \%$, two in $26.0 \%$, three in $22.1 \%$, four in $12.5 \%$, and five in $12.5 \%$. Impaired consciousness was most likely caused by acute occlusion of supra-aortic branches, such as RCCA or IA, and unlike chest pain, abdominal pain caused by ischemia of the celiac trunk artery or SMA was often atypical or was masked by chest pain. Morbidity and mortality increased rapidly if supra-aortic vessels were involved or if visceral organs were ischemic. Our findings have been supported by the findings of $\mathrm{Di}$ Eusanio M [30].

Owing to the uneven distribution of medical resources in China, many regional hospitals cannot perform surgical treatment of $\mathrm{AD}$ independently; they can only refer patients to higher-level hospitals or request experts at higher-level hospitals for assistance with consultation and surgical treatment. Thus, most patients with AADA admitted in our hospital were transferred from other hospitals. These patients underwent a preliminary examination at the regional hospital since the onset of the disease and were considered to be diagnosed with A; they were then referred to our hospital for treatment, where they underwent relevant examinations and preparations prior to surgery. This process took an average of 3 days; therefore, the inclusion criteria for being unable to undergo surgical treatment within 3 days from the onset of disease was included. According to previous reports, the mortality rate of patients with AADA who did not undergo surgical treatment had increased dramatically over time, with an hourly mortality rate of $1 \%$ and a 90 -day expected mortality rate of $70-90 \%[10,31]$.

\section{Limitations}

This is a single-center retrospective study and hence, the results are susceptible to a selection bias. We used an endpoint time of preoperative death within 3 days, which was the sole outcome. However, this limitation does not mitigate the importance of other outcome variables, such as nonfatal adverse events, complications, and patient functional status. Further study is required for analyzing these outcomes.

\section{Conclusions}

In our study, the individual risk factors for preoperative mortality were analyzed in patients with AADA, and a simple and effective risk assessment method was established to help clinicians quickly identify high-risk patients and make appropriate medical decisions. Further multicenter studies are needed for verifying the prospective data and the results of our study.

\section{Abbreviations}

AAD: Acute aortic dissection; AADA: Acute aortic dissection type A; Euro SCORE: European system for cardiac operative risk evaluation; AD: Aortic dissection; TTE: Transthoracic echocardiography; CTA: Computed tomography angiography; Lac: Lactic acid; ABG: Arterial blood gas; CTnT:Troponin T; WBC: White blood cell; RBC: Red blood cell; Hb: Hemoglobin; ALT: Alanine aminotransferase; AST: Aspartate aminotransferase; CREA: Serum creatinine; APTT: Activated partial thromboplastin time; EF: Ejection fraction; FL: False lumen; $\mathrm{TL}$ : True lumen; RCCA: Right common carotid artery; IA: Innominate artery; SMA: Superior mesenteric artery; RA: Renal artery; CIA: Common iliac artery;; OR: 
Odds ratios; Cl: Confidence intervals; ROC: Receiver operating characteristic; CHD: Coronary heart disease; AMI: Acute myocardial ischemia.

\section{Acknowledgements}

Not applicable.

\section{Authors' contributions}

KJT and YJ, contributions to conceptualization and design, or acquisition of data, or analysis and interpretation of data, involved in drafting, reviewing and editing the manuscript; WQJ, contributions to acquisition of data, involved in reviewing and editing the manuscript; $L Y$ and $Y C J$, analysis and interpretation of data, involved in reviewing and editing the manuscript; FRX, revising it critically for important intellectual content. All authors read and approved the final manuscript.

\section{Funding}

Supported by National Key Research and Development Program of China (2017YFC1308003). The funding body supported collection, professional advice from a statistician in Southern Medical University for suitable statistical analyses and from Wiley Editing Service for the quality of English. All the authors have nothing to disclose.

\section{Availability of data and materials}

The datasets used and/or analysed during the current study available from the corresponding author on reasonable request.

\section{Ethics approval and consent to participate}

This retrospective study was approved by the ethics committee of Guangdong Provincial People's Hospital, Guangdong Academy of Medical Sciences, Guangzhou, China (No.GDREC2018322H(R2)). Written and informed consent was obtained from the patients included in this study.

\section{Consent for publication}

Not applicable.

\section{Competing interests}

Not applicable.

\section{Declarations}

This retrospective study was approved by the ethics committee of Guangdong Provincial People's Hospital, Guangdong Academy of Medical Sciences, Guangzhou, China. Written informed consent was obtained from the patients and their legal relatives.

\section{Author details \\ ${ }^{1}$ Department of Cardiovascular Surgery, Guangdong Provincial Cardiovascu- lar Institute, Guangdong Provincial People's Hospital, Guangdong Acad- emy of Medical Sciences, Guangzhou 510080, China. ${ }^{2}$ The Second School of Clinical Medicine, Southern Medical University, Guangzhou 510515, China. ${ }^{3}$ Department of Cardiovascular Surgery, Guangdong Provincial People's Hospital, School of Medicine, South China University of Technology, Guang- zhou 510030, China.}

Received: 27 April 2020 Accepted: 26 November 2020

Published online: 03 December 2020

\section{References}

1. LeMaire SA, Russell L. Epidemiology of thoracic aortic dissection. Nat Rev Cardiol. 2011;8(2):103-13.

2. Anagnostopoulos CE, Prabhakar MJS, Kittle CF. Aortic dissections and dissecting aneurysms. Am J Cardiol. 1972;30(3):263-73.

3. Mark DB. Implications of cost in treatment selection for patients with coronary disease. Ann Thorac Surg. 1996;61(2):S12-5.

4. Hannan EL, Siu AL, Kumar D, Racz M, Pryor DB, Chassin MR. Assessment of coronary artery bypass graft surgery performance in New York, Is there a bias against taking high risk patients? Med Care. 1997;35(1):49-56.
5. Parsonnet $\mathrm{V}$, Dean $\mathrm{D}$, Bernstein $\mathrm{AD}$. A method of uniform stratification of risk for evaluating the results of surgery in acquired adult heart disease. Circulation. 1989;79:13-12.

6. Nashef SAM, Roques F, Michel P, Gauducheau E, Lemeshow S, Salamon R. European system for cardiac operative risk evaluation (EuroSCORE). Eur J Cardiothorac Surg. 1999;16:9-13.

7. Nashef SAM, Roques F, Sharples LD, Nilsson J, Smith C, Goldstone AR, et al. EuroSCORE II. Eur J Cardiothorac Surg. 2012;41:1-12.

8. Ge Y, Sun L, Zhu J, Liu Y, Cheng L, Chen L, et al. Can EuroSCORE II predict the mortality and length of intensive care unit stay after total aortic arch replacement with stented elephant trunk implantation for DeBakey type I aortic dissection? J Thorac Cardiovas Surg. 2013;61(7):564-8.

9. Ge Y, Chen L, Li C, Xia Y, Guo S, Liu W, et al. Validation of European system for cardiac operative risk evaluation II in predicting the mortality and prolonged intensive care unit stay after sun's procedure for stanford type a aortic dissection. Chin J Clin Thorac Cardiovasc Surg. 2015;22(1):23-7.

10. Rampoldi V, Trimarchi S, Eagle KA, Nienaber CA, Oh JK, Bossone E, et al. Simple risk models to predict surgical mortality in acute type A aortic dissection, the international registry of acute aortic dissection score. Ann Thorac Surg. 2007:83(1):55-61.

11. Leontyev S, Légaré JF, Borger MA, Buth KJ, Funkat AK, Gerhard J, et al. Creation of a scorecard to predict in-hospital death in patients undergoing operations for acute type a aortic dissection. Ann Thorac Surg. 2016;101(5):1700-6.

12. Augoustides JGT, Geirsson A, Szeto WY, Walsh EK, Cornelius B, Pochettino A, et al. Observational study of mortality risk stratification by ischemic presentation in patients with acute type A aortic dissection, the Penn classification. Nat Clinic Practic Cardiovasc Med. 2009;6(2):140-6.

13. Yi D, Duan W. Current status and prospects of diagnosis and treatment of aortic dissection in China. Chin Circulation J. 2013;28(1):1-2.

14. Gong M, Wu Z, Xu SJ, Guan XL, Li HY, Wang XL, et al. Protocol for creation of a risk scoring system for acute type A aortic dissection surgery. Int J Surg Protoc. 2019;14:19-23.

15. Shaheen AA, Kaplan GG, Hubbard JN, Myers RP. Morbidity and mortality following coronary artery bypass graft surgery in patients with cirrhosis, a population-based study. Liver Int. 2009;29(8):1141-51.

16. Suman A, Barnes DS, Zein NN, Levinthal GN, Connor JT, Carey WED, et al. Predicting outcome after cardiac surgery in patients with cirrhosis, a comparison of Child-Pugh and MELD scores. Clin Gastroenterol Hepatol. 2004;2(8):719-23.

17. Knipp BS, Deeb GM, Prager RL, Williams CY, Upchurch GR Jr, Patel HJ. A contemporary analysis of outcomes for operative repair of type A aortic dissection in the United States. Surgery. 2007;142(4):524-8.

18. Trimarchi S, Eagle KA, Nienaber CA, Rampoldi V, Jonker FHW, Vincentiis $C D$, et al. Role of age in acute type A aortic dissection outcome, report from the international registry of acute aortic dissection (IRAD). J Thorac Cardiovasc Surg. 2010;140(4):784-9.

19. Luo JL, Wu CK, Lin YH, Kao HL, Lin MS, Ho LY, et al. Type A aortic dissection manifesting as acute myocardial infarction, still a lesson to learn. Acta Cardiol. 2009;64(4):499-504.

20. Erbel R, Alfonso F, Boileau C, Dirsch O, Eber B, Haverich A, et al. Diagnosis and management of aortic dissection. Eur Heart J. 2001;22(18):1642-81.

21. Lee SI, Pyun SB, Jang DH. Dysphagia and hoarseness associated with painless aortic dissection, a rare case of cardiovocal syndrome. Dysphagia. 2006;21(2):129-32.

22. Cardozo C, Riadh R, Mazen M. Acute myocardial infarction due to left main compression aortic dissection treated by direct stenting. J Invasive Cardiol. 2004;16(2):89-91.

23. Chi QZ, He Y, Luan Y, Qin KR, Mu LZ. Numerical analysis of wall shear stress in ascending aorta before tearing in type A aortic dissection. Comput Biol Med. 2017;89:236-47.

24. Nathan DP, Xu C, Gorman JH, Fairman RM, Bavaria JE, Gorman RC, et al. Pathogenesis of acute aortic dissection, A finite element stress analysis. Ann Thorac Surg. 2011;91(2):458-63.

25. Lars OC, Ernst W, Uwe M, Ahmad A, Isabell H, Maria B, Christian DE, et al. Mortality in patients with acute aortic dissection type A: analysis of preand intraoperative risk factors from the German Registry for Acute Aortic Dissection Type A (GERAADA). Eur J Cardiothorac Surg. 2016;49(2):e52-3.

26. Mohamad B, Mark F, Matthew S, Matthew F, Deborah H, Manoj K, et al. Influences on early and mediumterm survival following surgical repair of the aortic arch. Aorta (Stamord). 2014;2(2):56-73. 
27. Orihashi K. Acute type a aortic dissection: for further improvement of outcomes. Ann Vasc Dis. 2012:5(3):310-20.

28. Geirsson A, Szeto WY, Pochettino A, McGarvey ML, Keane MG, Woo YJ, et al. Significance of malperfusion syndromes prior to contemporary surgical repair for acute type A dissection: outcomes and need for additional revascularizations. Eur J Cardiothorac Surg. 2007;32:255-62.

29. Augoustides JG, Szeto WY, Desai ND, Pochettino A, Cheung AT, Savino JS, et al. Classification of acute type A dissection: focus on clinical presentation and extent. Eur J Cardiothorac Surg. 2011;39:519-22.

30. Marco DE, Santi T, Himanshu JP, Stuart H, Toru S, Mark DP, et al. Clinical presentation, management, and short-term outcome of patients with type A acute dissection complicated by mesenteric malperfusion: observations from the International Registry of Acute Aortic Dissection. J Thorac Cardiovasc Surg. 2013;145(2):385-390.e1.

31. Mussa FF, Horton JD, Moridzadeh R, Nicholson J, Trimarchi S, Eagle KA. Acute aortic dissection and intramural hematoma, a systematic review. JAMA. 2016;316(7):754-63.

\section{Publisher's Note}

Springer Nature remains neutral with regard to jurisdictional claims in published maps and institutional affiliations.
Ready to submit your research? Choose BMC and benefit from:

- fast, convenient online submission

- thorough peer review by experienced researchers in your field

- rapid publication on acceptance

- support for research data, including large and complex data types

- gold Open Access which fosters wider collaboration and increased citations

- maximum visibility for your research: over $100 \mathrm{M}$ website views per year

At BMC, research is always in progress.

Learn more biomedcentral.com/submissions 